\title{
Endangerment of Pharmaceutical Waste Disposal in the Environment
}

\author{
Mahendran C. ${ }^{1}$, Midhun Kumar G.H. ${ }^{2}$, Parimala K. ${ }^{3}$, Shanmuga Priyan ${ }^{4}$ \\ ${ }^{l}$ Assistant Professor, Department of Community Medicine, Meenakshi Medical College Hospital and Research \\ Institute, Enathur, Kanchipuram, Tamilnadu, India, ${ }^{2}$ Associate Professor, Department of Community Medicine, \\ Meenakshi Medical College Hospital and Research Institute, Enathur, Kanchipuram, Tamilnadu, India, ${ }^{3}$ Professor \\ \& HOD, Department of Pharmacology, Meenakshi Medical College Hospital and Research Institute, Enathur, \\ Kanchipuram, Tamilnadu, India, ${ }^{2}$ Associate Professor, Department of Pharmacology, Meenakshi Medical College \\ Hospital and Research Institute, Enathur, Kanchipuram, Tamilnadu, India
}

\begin{abstract}
Disposal of pharmaceutical wastes in the environment leads to many losses and causes damage to the ecosystem. Plants, animals and human beings are put in endangerment due to the medicines and injections disposed in the environment. Toxic chemicals and substances exposed to the public nearby places causes many diseases such as respiratory syndromes and cancers skin infections and genetic disorders. Disposal in marine area pollutes the living atmosphere of aquatic organisms affects the ecosystem in unexpected ways. Considering this, environmental department should take effective precautions to protect and ensure the safety and peaceful living of beings in the environment. In this the article pollutants, toxic chemicals scavenged in the environment by the pharmaceutical industry, which has many adverse effects to the safety and a clean environment are discussed.
\end{abstract}

Keywords: Pharmaceutical waste, chemical industry, environment, pollution, pollutants.

\section{Introduction}

Pharmaceutical wastes are disposed in many forms such as the remained stocks of drugs, used needles, cottons with impurities and the surgical wastes, the expired medical kits and the cytotoxic wastes. All the wastes are considered as toxic to the ecosystem devastating materials. People are unaware of these consequences caused by the wastes from hospitals. Public concern level and voice against the illiterate activities done by pharmaceutical industries also leads to the impure ecosystem. Biggest worrying the bird

\section{Corresponding Author:}

Mahendran C.

Assistant Professor, Department of Community

Medicine, Meenakshi Medical College Hospital and

Research Institute, Enathur, Kanchipuram, Tamilnadu, India

e-mail: mahendranc@mmchri.ac.in vultures are affected by the diclofenac medicine, it is used in the treatment of inflammation in the veterinary hospitals. Antibiotic disposal in the environment, bacterial mutations are occurring and contamination strains are becoming resistant to such medicines which are of no use. In Waste water management the livestock feed is mixed with the disposal from pharmaceutical industries that disrupts the lives of the aquatic organisms. Ciprofloxacin, Oxytetracycline, sulfamethoxazole these are the major antibacterial drugs found to be resistant to many bacterial strains present in the pools and ponds of fresh water. Denitrifying and degradation of organic matter are affected the sewage wastes left in the environment. Such exposure to medicines and drugs led to the environment and mutation occurs in the soil born bacteria may cause adverse effects. On the whole high level of precaution must be taken before letting the exhausting materials from hospitals, laboratories and pharmaceutical industries which affects our ecosystem ${ }^{[1]}$.

Biomedical Wastes: Biological waste materials can be a liquid or a solid form disposed from the industries, 
hospitals from the treated patients. WHO says the toxic chemicals estimates that only ten percent of the disposals are infectious and $50 \%$ are non-infectious and remaining are non-toxic but consists the hazardous materials like methyl chloride and major concern is the toxic chemical transmits the virus and deadly bacteria from the wastes and not managed properly and just disposed as such in the environment. It seriously affects the living of slum people and people living around the rivers and roadside can lead to high range of environmental pollution ${ }^{[2]}$.

Water Pollution: Risks are categorized into three types such as genotoxicity, carcinogeneticity and toxicity create negative impact on the society in terms of environment disposal and wastages from industries and develops resistance in the microorganisms. Toxic chemicals inhaled by the organism show different mode of transmission from their natural behavior may be resistance and a species endangerment can happen. Maternal wastes such as hormonal tablets and drugs are toxic when it is exposed in the public environment. Some of the research, conducting institutes and industries letting the hazardous chemicals in the sewage that causes mutation in the organisms developed from the sewage wastes. These phenomena may accelerate the pathogens becoming resistant to the powerful drugs. This issue may cause changes in aquatic living organisms, some of the fish species are dead after the uptake of disposed drugs which also affects their fertility process ${ }^{[3]}$.

Soil Pollution: Mesophilic are the group of organisms living in moderate temperature is involved in the treatment of soil in recent times, which are indirectly affected by the pharmaceutical wastes. Sinking matters, microorganisms which enhance the fertility of the soil and organic matters are demolished when met with pharmaceutical wastes ${ }^{[4]}$. Major concern is active ingredients present in the environment which doesn't support the environmental safety. Some of the cost effective mechanisms are developed to find and determine the trace level of contaminants produced by the pharmaceutical wastes which affects the quality of life. The cooling water system and the floor, wash system have been introduced and it is established to control the soil by the pharmaceutical wastes ${ }^{[5]}$.

Aquatic Pollution: The pharmaceutical wastes are dumped in the sea and thrown without the care about the ecosystem and the organisms present in the sea. Discharged particles mixed in the seawater directly affect the organisms; especially it creates abiotic stress in the sea. The major accumulation of toxic chemical affects the tissues of the fish. Some of the parameters include $\mathrm{pH}$, sunlight, temperature should be taken into concern. The level of toxic chemical affecting the atmosphere should be eliminated and discarded from the sea to maintain the temperature level. The particles which are hard to eliminate from the sea affects the ecosystem which should be properly maintained to safeguard the earth to protect it from natural disasters formed in recent years $^{[6]}$.

Hazardous Wastes: Amoxcillin possesses antibacterial activity and it is present with betalactam ring this molecule is known to be cleavable. There are majorly two metabolites present in the compound especially amoxicilloic acid, amoxicillin diketopiperazine-2,5,-dione known as DIKETO. It has high allergens with high risk when it is disposed in the environment. Several method to determine the presence of this antibiotic is found. This low amount of antibiotic is found in soil, water and in the environment. Liquid chromatography is the technical method and powerful tool to determine the traces of amoxicillin present in the environment. This is the major pollutant and pharmaceutical wastes put into the environment ${ }^{[7]}$.

Chemotheraphy Waste: Bulk chemotherapy wastes are let into the environment which is considered as the most hazardous materials. P- and U hazardous materials which are low in limit to detect and destroy. The mostly preferred method is incineration the use of heat to destroy the materials that are toxic and when it's incorporated into the ecosystem it creates the unimaginable adverse effects due to the biological materials such as used syringes, infected gloves, tubing surgical gloves and aprons used for surgeries and treatment. The routine method of cleaning, preparation and administration of drugs should be taken care properly in the absence of such cleanliness leads to toxic effects in the normal people. There are safeties level should be properly followed by the industries and hospitals ${ }^{[8]}$.

Genotoxical Waste: The carcinogenicity is mostly referred as genotoxic and also referred as mutagens cause's effects in bacterial strain, aqua livings and also in human. These sorts of materials should be disposed with utmost care and the huge distracting waste material in soil in a cancer hospital and research institutes dealing with cancer. Drugs such as doxorubicin, phenacetin, lomustine and cyclosporin are carcinogenic and get easily accumulated in the soil without proper waste disposal ${ }^{[9]}$. 
With the help of contractors and public health volunteers involved in the disposal management, the wastes are disposed. There are certain laws, rules and regulations are maintained in the health department to maintain the safety of the public. While disposing and discarding the drugs in the soil or the clearance of drugs needs specialized companies who have taken care in disposing the waste has to report to the government. They also have special equipments and instruments to clear the waste from industries ${ }^{[10]}$.

Rules and regulations divided into six categories in India. The major categories are BMW (Biomedical waste). All the wastes from hospitals are established and the leap of wastes are generated were discarded on a daily basis. Mostly it was incinerated and deeply buried in the soil and to discard those debris hospitals should get approval regarding this from the corresponding authority. They need to have extra care while disposing the outdated products and expired medicines and drugs because they can interact with bio molecules present in the soil ${ }^{[11]}$.

Determinable effects are created after disposing the hormones, antibiotics and tablets to the environment. By flushing out the substances in ground water, river and in sewage water can create drastic changes in the microorganisms living in all the places. Even though people are careful while living near the slums the waste disposal indirectly affects the health of people by air, drinking water and in the soil. Instead, it directly affects the land, the wastes should be properly packed and disposed to prevent the birds, and animals surrounded in the ecosystem will be protected ${ }^{[12]}$.

HPLC (High performance liquid chromatography) has been found as one of the important qualitative and quantitative measure of drug used worldwide. HPLC is preferred in most pharmaceutical companies for the analytical technique. This technique is used for validation, formulation, production and to ensure the quality of drug these are pre steps taken before releasing the drug to the market. These analytical method can take even few hours or many days to validate the process of drug development ${ }^{[13]}$.

Bio-active compounds in the pharmaceutical wastes: Paddy is the most stable grains available for the global population. Paddy waste such as dusk and straw are let simply into the environment considering the no use of it. Annually, the straw and husk from the paddies are taken for the pharmacological potential as it can save the soil fertility and soil quality ${ }^{[14]}$.

Polysaccharides namely hemicellulose that are mainly differing from the several cellulose materials branched and have chain smaller in length. The unique nature of this material has attracted many industries, especially pharmaceutical industries. It is polymerized and used as disposable agents and identified in many natural plants which have highest composition of cellulosic material. Methylcellulose is considered as one of the other beneficial compounds dissolved in the alkaline solution and used further ${ }^{[15]}$.

The hospitals conduct the pharmaceutical waste disposal program called Disposal of used medicine program. This program is conducted to deliver the ideas of disposal and ways involved in the disposal of the expired medicines and products from the hospitals ${ }^{[16]}$.

\section{Conclusion}

Toxic chemicals and drugs causing severe effects and creates impact on the society by the pharmaceutical industries. People are affected by the poisonous material let by the industries in the environment. The ecosystem is altered with the consequences faced by the organisms living in soil, air and water. The government and public health department volunteers should involve in such matters to insist people about the drastic effects caused by the pharmaceutical wastes. Safety measures and risk assessment should be done before the disposal of drugs, medicines and products before disposal to ensure the safety of the ecosystem.

\section{Ethical Clearance: Nil}

Source of Funding: Meenakshi Academy of Higher Education and Research, Chennai, India

\section{Conflict of Interest: Nil}

\section{References}

1. Thomas F, World Health Organization. Pharmaceutical waste in the environment: a cultural perspective. Public health panorama. 2017;3(01):127-32.

2. Shaaban H, Alghamdi H, Alhamed N, Alziadi A, Mostafa A. Environmental contamination by pharmaceutical waste: assessing patterns of disposing unwanted medications and investigating the factors influencing personal disposal choices. J 
Pharmacol Pharm Res. 2018 Feb 10;1(1):003.

3. Grenni P. Effects of pesticides and pharmaceuticals on soil and water bacterial communities.

4. Guerin TF. Co-composting of pharmaceutical wastes in soil. Letters in applied microbiology. 2001 Oct 17;33(4):256-63.

5. Melcher RR. Pharmaceutical waste disposal by soil injection. Biotechnology and Bioengineering. 1962 Jun;4(2):147-51.

6. Gaw S, Thomas KV, Hutchinson TH. Sources, impacts and trends of pharmaceuticals in the marine and coastal environment. Philosophical Transactions of the Royal Society B: Biological Sciences. 2014 Nov 19;369(1656):20130572.

7. Deschamps E, Vasconcelos O, Lange L, Donnici CL, Silva MC, Sales JA. Management of effluents and waste from pharmaceutical industry in Minas Gerais, Brazil. Brazilian Journal of Pharmaceutical Sciences. 2012 Dec;48(4):727-36.

8. Pratyusha K, Gaikwad NM, Phatak AA, Chaudhari PD. Review on: Waste material management in pharmaceutical industry. Int. J. Pharm. Sci. Rev. Res. 2012;16(2):121-9.

9. Abna Sreedhar*, Madhvi Apte, Rashmi(2018) Pharmaceutical waste management. MallyaInt. J. Pharm. Sci. Rev. Res., 52(1).

10. Bungau S, Tit DM, Fodor K, Cioca G, Agop M, Iovan C, Cseppento DC, Bumbu A, Bustea C. Aspects regarding the pharmaceutical waste management in Romania. Sustainability. 2018 Aug; 10(8):2788.
11. Pore SM. Pharmaceutical waste from hospitals and homes: need for better strategies. Indian journal of pharmacology. 2014 Jul;46(4):459.

12. Patil PS, Kumbhoje SR, Patil SS. Pharmaceutical Waste Management-An Overview. Asian Journal of Pharmaceutical Research. 2015;5(2):118-21.

13. Khan H. Analytical Method Development in Pharmaceutical Research: Steps involved in HPLC Method Development. Asian Journal of Pharmaceutical Research. 2017;7(3):203-7.

14. Murtey MD, Seeni A. The phytochemical analysis and pharmacological potentials of husk and straw as paddy waste products. Journal of the Science of Food and Agriculture. 2020 Apr 5.

15. Ragab TI, El Awdan SA, Refaat A, Helmy WA. New applied pharmacological approach/trend on utilization of agro-industrial wastes. Environmental Science and Pollution Research. 2018 Sep 1;25(26):26446-60.

16. Pérez-Manríquez J, Escalona N, Pérez-Correa JR. Bioactive Compounds of the PVPP Brewery Waste Stream and their Pharmacological Effects. Mini-Reviews in Organic Chemistry. 2020 Feb 1;17(1):91-112.

17. Sasu S, Kümmerer K, Kranert M. Assessment of pharmaceutical waste management at selected hospitals and homes in Ghana. Waste Management \& Research. 2012 Jun;30(6):625-30. 